\title{
Role of Bio Farming in Nutraceutical Innovations
}

\author{
Hossein Shabanali Fami* and Mahsa Moetaghed \\ Faculty of Agricultural Economics and Development, Iran
}

*Corresponding author: Hossein Shabanali Fami, Faculty of Agricultural Economics and Development, P.O. Box. 4111, P.C. 31518-77871, Karaj, Iran

\begin{tabular}{lll}
\hline ARTICLE INFO & & ABSTRACT \\
\cline { 1 - 1 } $\begin{array}{ll}\text { Received: } \\
\text { Published: } \text { April 12, } 2019\end{array}$ April 17, 2019 & & $\begin{array}{l}\text { Citation: Hossein Shabanali Fami, Mahsa Moetaghed. Role of Bio Farming in Nutraceutical } \\
\text { Innovations. Biomed J Sci \& Tech Res 17(1)-2019. BJSTR. MS.ID.002958. }\end{array}$ \\
\hline
\end{tabular}

\section{Opinion}

Nowadays, there are debates among the scientists to develop farming systems which are able to produce safe and organic foods. According to FAO [1] food systems has to take healthy diets into account at different stages of food supply chain from production, handling, storage, processing, trade, and marketing into consumption. Today, agriculture at the world level needs to change and review the production methods and take into account the food health as one of the components of its development. This is closely linked to the production of healthy crops and promoting organic farming. Organic farming is recognized throughout the world as a new approach and system to agricultural development, which emphasizes the production of healthy products and safe food. Industrial chemicals (synthetic) such as herbicides, insecticides, fungicides, and livestock medicines are not used in the process of organic farming. In other words, the organic food industry is a production approach at the first stages of the food supply chain which safeguard farms for healthy food production Bourn et al. $[2,3]$. As a result, fresh and organic products have better taste and nutritional value than other conventional products, although in some cases, organic products do not satisfy the preference of consumers in terms of flavor Bourn et al. [2].

However, organic products have a small share of the global food market but expanding certificates and increasing the availability of these products in supermarkets has led to faster growth of these products in the food industry Raynolds [4]. The demand for these products is increasing due to the awareness of consumers about the nutritional and health values of them. The statistical assessment shows that the market value of organic products reached to 51 billion euros in 2012 Niggli [5]. The cultivated area of organic products in Iran is about 40 thousand hectares and these products are directly gathered from natural areas of approximately 80 thousand hectares. According to the information of the Committee on Biological Products, the total cultivation area of products that are produced in Iran without the use of pesticides and chemical fertilizers is about 240 hectares, which includes about 126 hectares of horticultural products and 114 thousand hectares of field crops. This account for about one and 2.7 percent of field crops and fruits respectively. This indicates a basic condition is available in Iran for developing organic farming which is rapidly growing during the past years Govahe Sabz Company [6].

Although organic farming has the benefits of preserving the environment and reducing soil erosion but most importantly, it contributes to producing healthy food products. There are undoubtedly many barriers to the establishment of an organic production system that can be summarized in different categories such as low yields, lack of national and regional standards for the production of organic products, high prices, and small markets that require government support and large investments to expand it Tayefe Soltankhani [7]. In fact, the organic food market is on the growth path, and organic food consumers generally regard these products as healthy, nutritious and safe food, and the consumption of these products is expanding due to the attention of today's man to their health and safety and the environment around them Hamzaoui Essoussi et al. [8]. Therefore, organic agriculture provides a healthy outlet to promote the market of functional food Govahe Sabz Company [6]. The term functional food was first used in Japan. It refers to food which has added value to human health and a function of disease prevention Micromarketmonitor [9]. functional foods play an outstanding role in the improvement of life standard and reducing healthcare Bigliardi et al. [10]. Functional foods play an important role in human health and safety, in addition to their nutritional values. In this regard, Rokhbakhsh et al. [11] investigated functional and probiotic foods. Their results showed that the importance of organic and functional foods has changed 
from its primary role as a source of energy and growth into their biological role to human health.

In addition, the market has turned into producing and consuming more functional foods. Ghanbari et al. [12] also studied the composition of food-medicine and the production of functional foods. Their results showed that safe and functional nutrition has an important impact on the health and well-being of people. Biologically active compounds of organic products play an important role in the health and safety of the community due to their confirmed role in human development and in reducing the risk of diseases. The use of biologically active compounds in fruits and vegetables helps fight heart disease, cancer, obesity, diabetes, and gastrointestinal disturbances. Functional foods in addition to their natural properties have beneficial health effects. They are used in different forms from fresh products to powder, syrups, etc. and contain mostly probiotics components, useful natural pigments, such as beta-carotene and lycopene, as well as omega$3 \mathrm{~s}$ and $6 \mathrm{~s}$, insoluble vegetable fibers, such as all types of bran and vegetable fibers and b-glucan from barley fiber. Given that the food market is expanding and is becoming more and more popular on a daily basis, it requires that infrastructure is created in the organic farming sector and help increase the production of these products. Therefore, In order nutraceuticals innovation should be considered as the core of any changes in farming systems to enable them to produce more functional foods.

\section{References}

1. (2018) FAO, Strengthening Sector Policies for Better Food Security and Nutrition Results.

ISSN: 2574-1241

DOI: 10.26717/BJSTR.2019.17.002958

Hossein Shabanali Fami. Biomed J Sci \& Tech Res

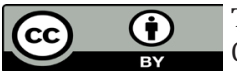

This work is licensed under Creative Commons Attribution 4.0 License

Submission Link: https://biomedres.us/submit-manuscript.php
2. Bourn D, Prescott J (2002) A comparison of the nutritional value, sensory qualities, and food safety of organically and conventionally produced foods. Critical reviews in food science and nutrition 42(1): 1-34.

3. Woese K, Lange D, Boess C, Bögl KW (1997) A comparison of organically and conventionally grown foods-results of a review of the relevant literature. Journal of the Science of Food and Agriculture 74(3): 281-293.

4. Raynolds LT (2004) The globalization of organic agro food networks. World development 32(5): 725-743.

5. Niggli U (2015) Sustainability of organic food production: Challenges and innovations. Proceedings of the Nutrition Society 74(1): 83-88.

6. Govahe Sabz (2016) Company Organic Agriculture in Iran and the World.

7. Tayefe Soltankhani A (2010) Organic farming and its role in food security. Shirinbayan Magazine 16: 34-35.

8. Hamzaoui Essoussi L, Zahaf M (2008) The decision making process of community organic food consumers: an exploratory study. Journal of Consumer Marketing 25(2): 95-104.

9. Micromarketmonitor (2019) Global Functional Food Market Research Report.

10. Bigliardi B, Galati F (2013) Innovation trends in the food industry: the case of functional foods. Trends in Food Science \& Technology 31(2): 118-129.

11. Rokhbakhsh Z, Keramat J (2015) Functional and probiotic foods. Paper presented at the National Conference on Technological Achievements of Food Science and Industries.

12. Ghanbari M, Saeedi M, Mortazavian AM (2016) Nutraceuticals and Functional Foods production. Clinical Excellence 5(1): 1-15.

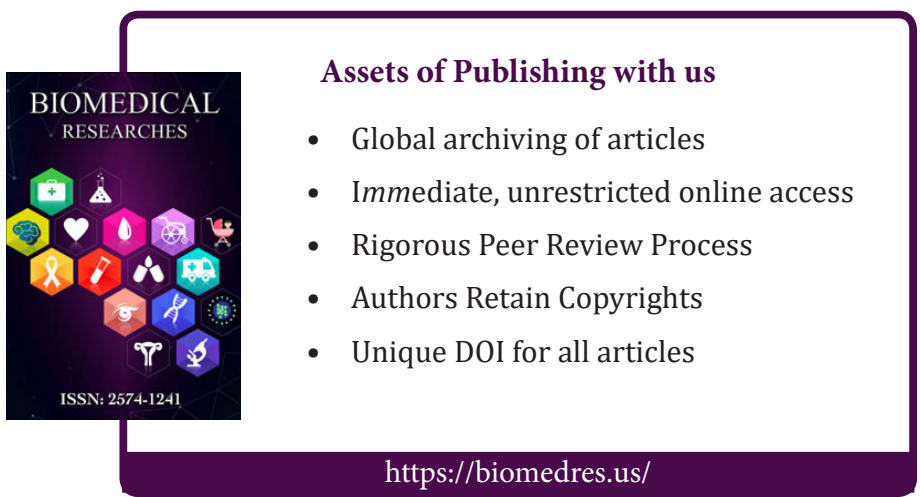

